\title{
AUDIT
}

\section{Frequency of proteinuria in type 2 diabetes mellitus seen at a diabetes centre in southern India}

\author{
V Mohan, R Meera, G Premalatha, R Deepa, P Miranda, M Rema
}

\begin{abstract}
The frequency of proteinuria was assessed in a cohort of 1848 diabetic patients attending a diabetes centre in south India. A total of 127 (6.9\%) patients had evidence of macroproteinuria and $49(2.5 \%)$ patients had microproteinuria. Thus overall 9.4\% of patients had diabetes related proteinuria. In addition, 70 patients $(3.8 \%)$ had evidence of proteinuria with no evidence of retinopathy. The frequency of both microproteinuria and macroproteinuria increased linearly with duration of diabetes. Multiple logistic regression analysis showed that duration of diabetes, serum creatinine, and glycated haemoglobin were risk factors for macroproteinuria.

(Postgrad Med f 2000;76:569-573)
\end{abstract}

Keywords: diabetic nephropathy; type 2 diabetes; south India

Type 2 diabetes in Asian Indians shows several differences from that seen in Europeans. The prevalence of diabetes is high, ${ }^{12}$ obesity is less common, ${ }^{34}$ the onset of diabetes is at a younger age, and genetic factors are strong. ${ }^{56}$ There are also reported differences with respect to occurrence of complications. Coronary heart disease appears to be more ${ }^{78}$ and peripheral vascular disease less common among type 2 Indian diabetic patients compared with Europeans. ${ }^{9}$ A recent report from our group suggests that the prevalence of diabetic retinopathy is similar to that seen in Europeans. ${ }^{10}$ There are reports particularly from the UK that suggest diabetic nephropathy is more common among the migrant Indians compared with the local European population. ${ }^{11}{ }^{12}$ There are very few data on the prevalence of nephropathy in diabetic patients from the Indian subcontinent. This paper presents data on proteinuria in type 2 diabetic patients seen at a diabetes centre in southern India.

\section{Patients and methods}

The study group comprised 1848 consecutive type 2 diabetic patients attending the $\mathrm{MV}$ Diabetes Specialities Centre, a large diabetes centre at Chennai in southern India, in whom complete records were available. During the study period from 1 December 1994 to 31 May 1995, 287 patients had to be excluded due to incomplete records, presence of urinary tract infection, or heart failure. There was no significant differences in the age, sex distribution, plasma glucose, or glycated haemoglobin (HbA1c) levels between these 287 patients and the 1848 patients included in the study. Type 2 diabetes was diagnosed based on the World Health Organisation criteria. ${ }^{13}$

In all study patients, a complete clinical work up was done including height, weight, and body mass index (BMI). The blood pressure recorded in the right upper limb in the sitting posture on two occasions at least 15 minutes apart and the mean of the two readings were taken. Patients were categorised as hypertensive if they were on antihypertensive treatment or if they had a systolic blood pressure $>140$ $\mathrm{mm} \mathrm{Hg}$ and/or diastolic blood pressure $>90$ mm Hg. ${ }^{14}$ The BMI was calculated using the formula: weight in kg divided by the height in $\mathrm{m}^{2}$. A fasting sample of blood was drawn after an overnight fast of 10 hours and the following investigations were done: plasma glucose, serum cholesterol, serum triglycerides, high density lipoprotein cholesterol, and serum creatinine. A standard breakfast was given as described previously ${ }^{15}$ and at 90 minutes a postprandial sample was drawn for glucose estimation.

Biochemical analysis were done on Corning Express Plus Auto Analyser (Corning, Medfield, MA, USA) using kits supplied by Boehringer Mannheim (Mannheim, Germany). Fasting and postprandial plasma glucose (glucose oxidase method), serum cholesterol (CHOD-PAP method), serum triglycerides (GPO-PAP method), and serum creatinine (modified kinetic method of Jaffe) were estimated in all patients. HbAlc was estimated by high pressure liquid chromatography using the Variant machine (Bio Rad, Hercules, CA, USA). Urinary protein was measured on a spot urine by the sulphosalicylic acid technique. The mean interassay and intra-assay coefficients of variation were $5.6 \%$ and $11.2 \%$ respectively. Creatinine was measured using Jaffe's method (coefficient of variation = $5.7 \%)$. Proteinuria was calculated based on protein creatinine ratio. ${ }^{16}$ The usefulness of this method has been documented previously and shown to correlate well with the 24 hour protein excretion ${ }^{17}$ and also with urinary albumin excretion rate. ${ }^{18}$
1999

Accepted 20 December 1999 
Table 1 Prevalence of proteinuria in type 2 diabetes; results are number (\%)

\begin{tabular}{lccc}
\hline Study groups & Total $(n=1848)$ & Male $(n=1137)$ & Female $(n=711)$ \\
\hline No proteinuria & $1604(86.8)$ & $981(86.3)$ & $623(87.6)$ \\
Macroproteinuria & $127(6.9)$ & $85(7.5)$ & $42(5.9)$ \\
Microproteinuria & $47(2.5)$ & $32(2.8)$ & $15(2.1)$ \\
Proteinuria without retinopathy & $70(3.8)$ & $39(3.4)$ & $31(4.4)$ \\
\hline
\end{tabular}

DEFINITIONS

Proteinuria

Only those patients with proteinuria measurements made on at least two consecutive visits were included. None had any evidence of urinary tract infection clinically and urine cultures were sterile. Patients with persistent proteinuria-that is, protein concentration $\geqslant 500 \mathrm{mg} /$ day in the presence of any diabetic retinopathy, were classified as "macroproteinuric". Patients were classified as "microproteinuric" if their protein concentration was found in the range of $150-499 \mathrm{mg} /$ day in the presence of diabetic retinopathy. Patients with protein $\geqslant 500 \mathrm{mg} /$ day but who had no evidence of retinopathy were considered as having "proteinuria without retinopathy". Renal insufficiency was defined as serum creatinine $>133$ $\mu \mathrm{mol} . / 1$.

\section{Retinopathy}

The ocular fundi were examined by a retinal specialist both by direct and indirect ophthalmoscopy, after mydriasis. Retinopathy when present was classified as non-proliferative diabetic retinopathy and proliferative diabetic retinopathy. Non-proliferative diabetic retinopathy was diagnosed when there was evidence of microneurysms, dot haemorrhages, exudates, or cotton wool spots in the absence of any new vessels or advanced diabetic eye disease. Proliferative diabetic retinopathy was diagnosed when any new vessels were present or if there was evidence of fibrous retinitis proliferans, vitreous haemorrhage, retinal detachment, or other features of advanced diabetic eye disease.

Ischaemic heart disease

Ischaemic heart disease was considered to be present when either myocardial ischaemia or infarction was present.

Myocardial ischaemia was diagnosed if there was a history of exertional chest pain (angina) with unequivocal $\mathrm{T}$ wave changes in the electrocardiogram (ECG), but no evidence of infarction.

Myocardial infarction was diagnosed if there was a classical history of chest pain documented by hospital records along with ST or Q wave changes on the ECG suggestive of recent or past myocardial infarction.

\section{Neuropathy}

Neuropathy was defined as bilateral absence of ankle jerks and/or bilateral distal sensory neuropathy. The latter was documented by biothesiometry (Bio Medical Instrument Co, Newbury, Ohio, USA) as previously described. ${ }^{19}$

\section{Peripheral vascular disease}

Peripheral vascular disease was diagnosed using Doppler recording of pressure tracings using a KODY vaslab machine (Kody Labs, Madras). An ankle branchial pressure index of 0.8 or less was considered as evidence of peripheral vascular disease.

STATISTICS

Statistical analysis were done using SPSS PC + 4.0.1. version. One way analysis of variance with Tukey's honestly significant difference test

Table 2 Clinical characteristics of study groups

\begin{tabular}{|c|c|c|c|c|}
\hline \multirow[b]{2}{*}{ Variable } & \multicolumn{4}{|l|}{ Study groups } \\
\hline & $\begin{array}{l}\text { No proteinuria } \\
(n=1604)\end{array}$ & $\begin{array}{l}\text { Microproteinuria } \\
(n=47)\end{array}$ & $\begin{array}{l}\text { Macroproteinuria } \\
(n=127)\end{array}$ & $\begin{array}{l}\text { Proteinuria without } \\
\text { retinopathy }(n=70)\end{array}$ \\
\hline Age (years) & $52(11)$ & $57(9)^{\star}$ & $55(8)^{\star}$ & $56(12)$ \\
\hline Age of diagnosis of diabetes (years) & $45(10)$ & $44(9)$ & $42(9)^{\star}$ & 49 (11) \\
\hline Duration of diabetes (years) & $6(6)$ & $13(7)^{\star}$ & $13(7)^{\star}$ & $6(6) \pm$ \\
\hline $\mathrm{BMI}\left(\mathrm{kg} / \mathrm{m}^{2}\right)$ & $25.0(4.1)$ & $24.8(4.7)$ & $23.4(3.5) \dagger$ & $27.0(5.2) \S$ \\
\hline Systolic blood pressure (mm Hg) & $135(16)$ & $142(17)^{\star}$ & $147(20)^{\star}$ & $143(21)$ \\
\hline Diastolic blood pressure (mm Hg) & $84(7)$ & $85(7)$ & $88(11)^{\star}$ & $88(11)^{\star}$ \\
\hline Hypertension (\%) & $37 \%$ & $47 \% \star \star$ & $67 \%+$ & $61 \%$ \\
\hline
\end{tabular}

${ }^{\star}$ Significantly different from group with no proteinuria $(\mathrm{p}<0.05)$.

$t \mathrm{p}<0.05$ when compared with groups with microproteinuria and no proteinuria.

$\ddagger$ Significantly different from groups with microproteinuria and macroproteinuria $(p<0.05)$.

$\S$ Significantly different from other groups with proteinuria.

Table 3 Biochemical characteristics of study groups

\begin{tabular}{|c|c|c|c|c|}
\hline \multirow[b]{2}{*}{ Variable } & \multicolumn{4}{|l|}{ Study groups } \\
\hline & $\begin{array}{l}\text { No proteinuria } \\
(n=1604)\end{array}$ & $\begin{array}{l}\text { Microproteinuria } \\
(n=47)\end{array}$ & $\begin{array}{l}\text { Macroproteinuria } \\
(n=127)\end{array}$ & $\begin{array}{l}\text { Proteinuria without } \\
\text { retinopathy }(n=70)\end{array}$ \\
\hline $\mathrm{FPG}(\mathrm{mmol} / \mathrm{l})$ & $10.4(3.9)$ & $13.3(4.5)^{\star}$ & $12.2(4.9)^{\star}$ & $12.0(4.3)^{\star}$ \\
\hline PP-PG (mmol/l) & $16.4(5.3)$ & $19.7(5.3)^{\star}$ & $18.0(5.7)^{\star}$ & $18.0(5.9)^{\star}$ \\
\hline $\mathrm{HbA} 1 \mathrm{c}(\%)$ & $9.3(2.2)$ & $10.6(1.9)^{\star}$ & $10.1(2.2)^{\star}$ & $10.3(2.4)^{\star}$ \\
\hline Cholesterol $(\mathrm{mmol} / \mathrm{l})$ & $5.4(1.1)$ & $5.6(1.2)$ & $5.7(1.4)^{\star}$ & $5.8(1.5)^{\star}$ \\
\hline Triglycerides $(\mathrm{mmol} / \mathrm{l})$ & $2.0(1.4)$ & $2.0(1.6)$ & $2.1(1.5)$ & $2.2(1.3)$ \\
\hline Serum creatinine $(\mu \mathrm{mol} / \mathrm{l})$ & $72.6(18.6)$ & $78.4(21.5)$ & $100.6(34.3) \ddagger$ & $91.4(31.6) \dagger$ \\
\hline
\end{tabular}

*Significantly different compared with group with no proteinuria $(\mathrm{p}<0.05)$.

+ Significantly different compared with groups with microproteinuria and no proteinuria $(p<0.05)$.

$\ddagger$ Significantly different compared with other groups.

FPG: fasting plasma glucose; PP-PG: postprandial plasma glucose. 


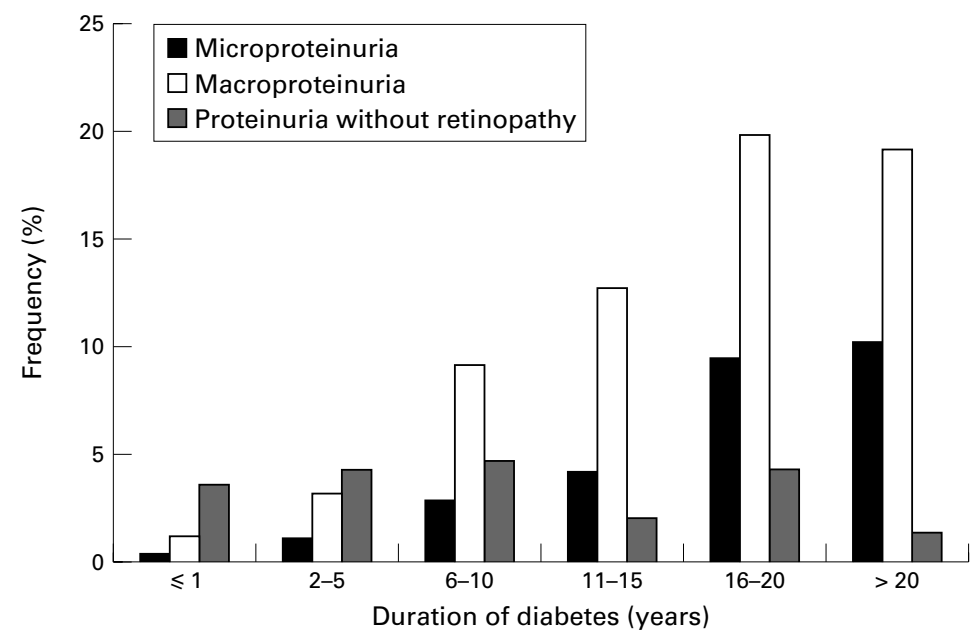

Figure 1 Frequency of proteinuria in relation to duration of diabetes.

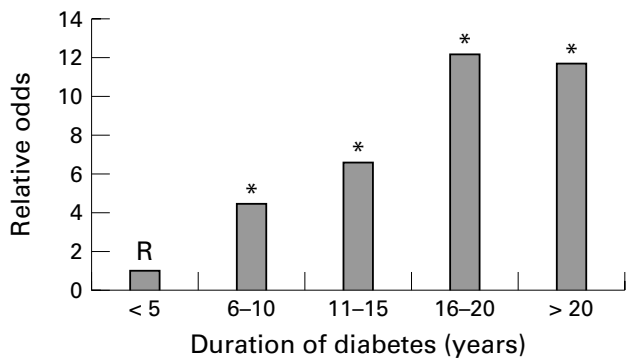

Figure 2 Relative odds ratio for macroproteinuria in relation to duration of diabetes. Duration $<5$ years is taken as the reference $(R)$.

was used to compare the means of continuous variables in more than two groups. Multiple logistic regression analyses was done using macroproteinuria as the dependent variable and the variables tested included age, BMI, smoking, duration of diabetes, fasting and postprandial plasma glucose, $\mathrm{HbAlc}$, serum cholesterol, serum triglycerides, serum creatinine, and systolic and diastolic blood pressure.

\section{Results}

Table 1 shows the frequency of macroproteinuria and microproteinuria. A total of 127 patients $(6.9 \%)$ had macroproteinuria and 47 patients $(2.5 \%)$ had microproteinuria. An additional 70 patients $(3.8 \%)$ had proteinuria without retinopathy. There was no significant difference between males and females in the occurrence of macroproteinuria or microproteinuria or proteinuria without retinopathy.

Table 2 shows the clinical characteristics of the study groups. The patients with proteinuria were older those with no proteinuria. The macroproteinuric patients had a significantly

Table 4 Results of multiple logistic regression-groups with macroproteinuria $v$ no proteinuria

\begin{tabular}{lllll}
\hline Variable & Regression coefficient & SE & $p$ Value & OR (95\% CI) \\
\hline Duration & 0.53 & 0.14 & $<0.0001$ & $1.7(1.3$ to 2.3$)$ \\
HbA1c & 0.55 & 0.18 & 0.003 & $1.7(1.2$ to 2.5$)$ \\
Creatinine & 0.92 & 0.15 & $<0.0001$ & $2.5(1.9$ to 3.4$)$ \\
\hline
\end{tabular}

Macroproteinuria was used as the dependent variable. The following categories were used for continuous variables: age, 10 year intervals; BMI, 3 units; fasting blood glucose, $1.39 \mathrm{mmol} / \mathrm{l}$; serum cholesterol, $0.65 \mathrm{mmol} / 1$; serum triglycerides, $0.28 \mathrm{mmol} / \mathrm{l}$; serum creatinine, $8.84 \mu \mathrm{mol} / \mathrm{l}$ duration of diabetes, five year intervals; and hypertension, systolic blood pressure $>140 \mathrm{~mm} \mathrm{Hg}$ or diastolic blood pressure $>90 \mathrm{~mm} \mathrm{Hg}$. earlier onset of diabetes compared with the non-proteinuric group and the group with proteinuria without retinopathy. The duration of diabetes was higher in both macroproteinuria and microproteinuria groups compared with the groups with no proteinuria and proteinuria without retinopathy. The macroproteinuric group had a lower BMI compared with the other groups. All the proteinuric patients had increased systolic blood pressure compared with non-proteinuric subjects. However diastolic blood pressure was higher only in the groups with macroproteinuria and proteinuria without retinopathy compared with the nonproteinuric group.

Table 3 shows the biochemical characteristics of the study groups. Fasting plasma glucose and postprandial plasma glucose were significantly higher in all the proteinuric groups compared with the non-proteinuric groups. $\mathrm{HbA} 1 \mathrm{c}$ levels were also significantly higher in all groups with proteinuria. Serum creatinine levels were higher in the macroproteinuric group compared with the other two groups. Serum cholesterol levels were significantly higher in the patients with macroproteinuria and proteinuria without retinopathy compared with non-proteinuric groups. Serum triglycerides levels were not significantly different in the three groups.

Figure 1 shows the frequency of microproteinuria and macroproteinuria in relation to the duration of diabetes. There was an increase in frequency of macroproteinuria in patients who had diabetes of up to 20 years' duration after which there was a slight decrease. The frequency of microproteinuria continued to increase even beyond 20 years. Trend $\chi^{2}$ tests showed that this increase in frequency was statistically significant both in the macroproteinuric and microproteinuric groups $(\mathrm{p}<0.001)$. The frequency of proteinuria in the group with proteinuria without retinopathy showed no significant increase with duration of diabetes.

Figure 2 shows the odds ratio for occurrence of macroproteinuria in relation to duration of diabetes. Taking duration $<5$ years as the reference, the odds ratios were $4.0,6.0,12.0$, and 11.0 for duration of $6-10$ years, $11-15$ years, $16-20$ years, and $>20$ years respectively.

Table 4 shows the results of the multiple logistic regression analysis using macroproteinuria as the dependent variable. Duration of diabetes, serum creatinine, and $\mathrm{HbA} 1 \mathrm{c}$ showed a significant association with macroproteinuria.

Table 5 shows the prevalence of various complications in the study groups. The prevalence of proliferative diabetic retinopathy was significantly higher in macroproteinuric patients compared with those with microproteinuria $(\mathrm{p}<0.0001)$. The group with proteinuria without retinopathy had a lower prevalence of neuropathy compared with other study groups. The prevalence of neuropathy was the same in the microproteinuric and macroproteinuric groups. Ischaemic heart disease was more common in the macroproteinuric patients compared with other study groups $(\mathrm{p}<0.001)$. Peripheral vascular disease was 
Table 5 Correlation between proteinuric and other complications of diabetes; results are number (\%)

\begin{tabular}{lllll}
\hline Parameters & $\begin{array}{l}\text { No proteinuria } \\
(n=1604)\end{array}$ & $\begin{array}{l}\text { Microproteinuria } \\
(n=47)\end{array}$ & $\begin{array}{l}\text { Macroproteinuria } \\
(n=127)\end{array}$ & $\begin{array}{l}\text { Proteinuria without } \\
\text { retinopathy }(n=70)\end{array}$ \\
\hline $\begin{array}{l}\text { Ischaemic heart disease } \\
\text { Peripheral vascular disease }\end{array}$ & $164(10)$ & $7(15)$ & $33(26)^{\star}$ & $13(19)$ \\
$\begin{array}{l}\text { Neuropathy } \\
\text { Retinopathy }\end{array}$ & $704(44)$ & $4(9)^{\star}$ & $6(5)$ & $3(4)$ \\
$\quad$ None & $1321(83)$ & $20(43)$ & $53(42)$ & $21(30)$ \\
NPDR & $265(16)$ & 0 & 0 & 0 \\
PDR & $18(1)$ & $25(96)$ & $83(65) \dagger$ & 0 \\
Renal insufficiency & $6(0.4)$ & $2(4)$ & $44(35) \dagger$ & 0 \\
\hline
\end{tabular}

*Significantly different from group with no proteinuria $(\mathrm{p}<0.05)$.

†Significantly different compared with groups with microproteinuria and no proteinuria $(\mathrm{p}<0.05)$.

NPDR: non-proliferative diabetic retinopathy; PDR: proliferative diabetic retinopathy.

uncommon in all three groups including those with macroproteinuria. The prevalence of renal insufficiency was higher in those with macroproteinuria and with proteinuria without retinopathy compared with other groups.

\section{Discussion}

The prevalence of type 2 diabetes in the Indian subcontinent is rising at an alarming rate from a figure of $8.6 \%$ in 1992 to $11.3 \%$ in $1996 .^{20}$ India already ranks number one in the world in the total number of diabetic patients, ahead of China and USA, and the prediction is that the trend will continue in the future. ${ }^{21}$ In this context, studies on the morbidity due to diabetes in this population are extremely valuable for planning future health programmes. Although ideally population based studies should be done, there are financial and logistic constraints in developing countries. This study reports on the frequency of proteinuria in a large unselected cohort of type 2 diabetic patients attending a diabetes centre. One cannot exclude referral bias (that is, patients with nephropathy being specifically referred to our centre) affecting the results of this study. However this is unlikely to be very significant for several reasons: firstly, the frequency of proteinuria is comparable to that reported in an earlier study ${ }^{22}$ and lower than that reported in another. ${ }^{23}$ Secondly there are no specific renal services offered at the centre to specifically attract patients with nephropathy.

The present study shows that overall, 9.4\% of patients have diabetes related proteinuria and $3.8 \%$ of patients have proteinuria with evidence of retinopathy. After 16-20 years' duration, the frequency of diabetes related proteinuria increases to $29 \%$ (20\% macroproteinuria and $9 \%$ microproteinuria) and remains constant thereafter. The mortality due to diabetic renal disease in type 2 diabetic patients is usually lower than that reported in type 1 patients. ${ }^{24}{ }^{25}$ Stephenson et al reported that type 1 and type 2 diabetic patients had similar prevalence rates of proteinuria. ${ }^{26}$ In type 1 diabetes, proteinuria is associated with nephropathy and renal failure ${ }^{24}{ }^{25}$ while in type 2 diabetic patients proteinuria is widely associated with cardiovascular rather than renal disease. ${ }^{27}{ }^{28}$ Thus among Europeans, diabetic nephropathy is reported to develop in $35 \%$ of patients with type 1 and $3 \%-15 \%$ of patients with type 2 diabetes. ${ }^{29-31}$ Prevalence rates would of course vary widely depending on the methodology and definitions used for diabetic nephropathy. Fabre et al reported a prevalence of $48 \%$ with abnormal protein excretion $(>150$ $\mathrm{mg}$ in 24 hours) among 510 type 2 diabetic patients and $16 \%$ had protein excretion in excess of $500 \mathrm{mg}$ in 24 hours. ${ }^{32}$

Studies from the UK have shown that among migrant Asian Indians, the prevalence of both diabetic and "non-diabetic" renal disease is higher compared with Europeans. ${ }^{11}{ }^{13}{ }^{33-35}$ John et al in a report from Vellore in southern India found that $8.4 \%$ of patients had persistent proteinuria (over $500 \mathrm{mg}$ in 24 hours). ${ }^{22}$ In addition, $27.5 \%$ of patients had microproteinuria. They also found a high degree of correlation between microproteinuria and microalbuminuria in their study. Because of cost constraints, we choose to measure microproteinuria in this study as it is much less expensive.

Vijay et al, working at another diabetes centre at Chennai, found a much higher prevalence of proteinuria $(18.7 \%) .{ }^{23}$ However the latter study was confined to inpatients, that is, patients admitted to hospital. This would undoubtedly introduce an additional bias of more severely ill patients being included in the study and this could explain the difference between our two studies.

The results of our logistic regression analysis suggest that duration of diabetes, $\mathrm{HbAlc}$, and serum creatinine are associated with proteinuria. The duration of diabetes has been shown to be a risk factor for nephropathy by almost all earlier studies. ${ }^{36-38}$ The recent Diabetes Control and Complications Trial Research Group ${ }^{39}$ and UK Prospective Diabetes Group ${ }^{36}$ studies have shown the impact of blood glucose control on reducing risk of retinopathy and nephropathy. The present study was carried out at the time of first presentation of the patient at our centre and hence the majority of patients had uncontrolled diabetes. Even so, both the proteinuric groups had higher HbAlc levels and this emphasises the need for good control of diabetes in the prevention of nephropathy.

The association with serum creatinine is to be expected as the occurrence of renal insufficiency is only the next stage in the natural history of diabetic nephropathy. It is of interest that blood pressure did not come out significantly in the logistic regression analysis. This could be explained by the small number of patients with macroproteinuria and microproteinuria. Table 2 however shows the systolic blood pressure was significantly high in both the macroproteinuric and microproteinuric 
groups and diastolic blood pressure in the macroproteinuric group. Vijay et al have shown that the initial $\mathrm{HbA} 1 \mathrm{c}$ value and initial systolic blood pressure were predictive factors for development of proteinuria in a small cohort of type 2 diabetic patients followed up by them. ${ }^{40}$

In a previous study, we showed that overall $34 \%$ of our type 2 diabetic patients had evidence of retinopathy and after 20 years' duration, $85 \%$ of patients had retinopathy which included $73 \%$ with non-proliferative diabetic retinopathy and $11.9 \%$ with proliferative diabetic retinopathy. ${ }^{10}$ In the present study, we found that even in the non-proteinuric group, $17 \%$ had diabetic retinopathy. The proteinuria without retinopathy group by definition had absence of retinopathy. It could be argued that some of these patients could indeed have diabetic nephropathy as retinopathy need not always be present in patients with nephropathy. Renal biopsies of such patients show that some of them would have changes consistent with diabetic nephropathy while $12 \%$ to $78 \%$ of such patients have been shown in different studies to have features of "non-diabetic" glomerulopathies like glomerulonephritis and other conditions. ${ }^{41}{ }^{42}$

In conclusion, given the large numbers of persons with diabetes in India, the numbers of diabetic patients with nephropathy is undoubtedly enormous. With the prevalence of diabetes on the increase, this could produce major constraints on health care budgets in the future. This urgently calls for not only good control of diabetes to prevent nephropathy but also to address the larger issue of primary prevention of diabetes, that is, reduction in the prevalence of diabetes itself by aggressive life style modifications.

We thank M/s, Serdia Pharmaceuticals (India) Ltd, Mumbai, for financial assistance for this project. statistical analysis.

1 Ramachandran A, Jali MV, Mohan V, et al. High prevalence of diabetes in an urban population in south India. $B M \mathcal{F}$ 1988;297:587-90

2 Mohan V, Ramachandran A, Viswanathan M. Tropical diabetes. In: Alberti KGMM, Krall LP, eds. Diabetes annual/2. Amsterdam: Elsevier Science, 1986: 30-8.

3 Mohan V, Ramachandran A, Snehalatha C, et al. High prevalence of maturity onset diabetes of the young (MODY) among Indians. Diabetes Care 1985;8:371-4.

4 Mohan V, Alberti KGMM. Diabetes in the tropics. In: Alberti KGMM, Defronzo RA, Keen $\mathrm{H}$, et al, eds. International textbook of diabetes mellitus. Vol II. Chichester: International textbook of diabet

5 Mohan V, Sharp PS, Aber V, et al. Family histories of Asian Mohan V, Sharp PS, Aber V, et al. Family histories of Asian
Indian and European NIDDM patients. Practical Diabetes 1986;3:254-6.

6 Viswanathan M, Mohan V, Snehalatha C, et al. High prevalence of type 2 (non-insulin dependent) diabetes among offspring of conjugal type 2 diabetic parents in south India. Diabetologia 1985;28:907-10.

7 Mohan V, Premalatha G, Sastry NG. Ischaemic heart disease in south Indian NIDDM patients-a clinic based study on 6597 NIDDM patients. International fournal of Diabetes in Developing Countries 1995;15:64-7.

8 Mckeigue P, Miller GJ, Marmot MG. Coronary artery disease in south Asian overseas: a review. 7 Clin Epidemio 1989;41:597-8

9 Mohan V, Premalatha G, Sastry NG. Peripheral vascular disease in non insulin dependent diabetes mellitus in south India. Diabetes Res Clin Pract 1995;27:235-40.

10 Rema M, Ponnaiya M, Mohan V. Prevalence of retinopathy in non insulin dependent diabetes mellitus in southern In non insulin dependes Res Clin Pract 1996;34:29-36.

11 Burden AC, McNally PG, Feehally J, et al. Increased incidence of end-stage renal failure secondary to diabetes
mellitus in Asian ethnic groups in the United Kingdon. Diabet Med 1992;9:641-5.

12 Samanta A, Burden C, Feehally J, et al. Diabetic renal disease; differences between Asian and white caucasians. BMF 1986;293:366-7.
13 World Health Organisation. WHO study group report on diabetes mellitus. WHO technical report series No 727 . Geneva: WHO, 1985.

14 Joint National Committee on Detection, Evaluation and Treatment of High Blood Pressure. The fifth report of the Joint National Committee on Detection, Evaluation and Treatment of High Blood Pressure (JNC-V). Arch Intern Med 1993;153:154-83.

15 Snehalatha C, Ramachandran A, Mohan V, et al. Pancreatic beta cell response in insulin treated NIDDM patientslimitations of a random C-peptide measurement. Diabeté and Metabolismé 1987;13:27-30

16 Varley H, Gowenlock AH, Bell M. Practical clinical biochemistry. London: Heinemann, 1980: 600-1.

17 Snehalatha C, Krishnapriya PK, Ramachandran A, et al. Estimation of 24 hours proteinuria-comparison of two methods. Fournal of Diabetic Association of India 1987;27:735 .

18 Zelmanovitz T, Gross JL, Oliveria J, et al. Proteinuria is still useful for the screening and diagnosis of overt diabetic nephropathy. Diabetes Care 1998;21:1076-9.

19 Ramachandran A, Mohan V, Kumaravel TS, et al. Peripheral neuropathy in tropical pancreatic diabetes. Acta Diabetologica Latina 1986;23:135-40.

20 Ramachandran A, Snehalatha C, Latha E, et al. Rising prevalence of NIDDM in an urban population in India. Diabetologia 1997;40:232-7.

21 King H, Auberti RE, Herman WH. Global burden of diabetes, 1995-2025. Prevalence, numerical estimates and projections. Diabetes Care 1998;21:1414-31.

22 John L, Sundar Rao PSS, Kanagasabapathy SS. Prevalence of diabetic nephropathy in non-insulin dependent diabetics. Indian 7 Med Res 1991;94:24-29.

23 Vijay V, Snehalatha C, Ramachandran A, et al. Prevalence of proteinuria in non insulin dependent diabetes. F Assoc Physicians India 1994;42:792-4.

24 Andersen AR, Christiansen JS, Andersen JK, et al. Diabetic nephropathy in type 1 (insulin dependent) diabetes: an epidemiological study. Diabetologia 1983;25:496-501.

25 Krolewski AS, Warram JH, Christlieb AR, et al. The changing natural history of nephropathy in type 1 diabetes. $A m$ F Med 1985;78:785-94.

26 Stephenson JM, Kenny S, Stevens LK, et al. Proteinuria and mortality in diabetes: the WHO multinational study of vascular disease in diabetes. Diabet Med 1995;12:149-55.

27 Mogensen CE. Microalbuminuria predicts clinical proteinuria and early mortality in maturity onset diabetes. $N$ Engl f Med 1984;310:356-60.

28 Marshall SM, Alberti KGMM. Comparison of prevalence and associated features of abnormal albumin excretion in insulin dependent and non insulin dependent diabetics. $Q \mathcal{F}$ Med 1989;70:67-71.

29 Tung P, Levin SR. Nephropathy in non insuiln dependent diabetes mellitus. Am f Med 1988;85:131-6.

30 Schmitz A, Vaeth M. Microalbuminuria: a major risk factor in non insulin dependent diabetes. A 10 year follow-up study of 503 patients. Diabet Med 1988;5:126-34.

31 Borch-Johnsen K, Anderson PK, Deckert T. The effect of proteinuria on relative mortality in type 1 (insulin dependent) diabetes mellitus. Diabetologia 1985;28:590-6.

32 Fabre J, Balant LP, Dayer PG, et al. The kidney in maturity onset diabetes mellitus: a clinical study of 510 patients. Kidney Int 1982;2:730-8.

33 Allawi J, Rao PV, Gilbert R, et al. Microalbuminuria in non insulin dependent patients. BMF 1988;296:462-6.

34 Gujral JS, Burden AC, Iqbal J, et al. The prevalence of chronic renal failure in known diabetic and non diabetic white caucasians and south Asians. Practical Diabetes International 1997;14:71-4

35 Mather HM, Chaturvedi N, Kehely AM. Comparison of prevalence and risk factors for microalbuminuria in south Asians and Europeans with type 2 diabetes mellitus. Diabet Med 1998;15:672-7.

36 UK Prospective Diabetes Study (UKPDS) Group. Intensive blood glucose control with sulphonylureas or insulin compared with conventional treatment and risk of complications in patients with type 2 diabetes (UKPDS 33). Lancet 1998;352:1-18.

37 Collins VR, Dowse GK, Plehwe WE, et al. High prevalence of diabetic retinopathy and nephropathy in Polynesians of western Samao. Diabetes Care 1995;18:1140-9.

38 Klein R, Klein BEK, Moss SE. Incidence of gross proteinuria in older onset diabetes. A population based perspective. Diabetes 1993;42:381-9.

39 Diabetes Control and Complications Trial Research Group. The effect of intensive treatment of diabetes on the development and progression of long term complications in insulin dependent diabetes mellitus. N Engl F Med 1993;329:97786.

40 Vijay V, Snehalatha C, Ramachandran A, et al. Proteinuria in NIDDM in South India: analysis of predictive factors. Diabetes Res Clin Pract 1995;28:41-6.

41 John C, Date A, Korula A, et al. Non-diabetic renal disease in non insulin dependent diabetics in a south Indian hospital. Nephron 1994;67:441-3.

42 Olsen S, Mogensen CE. How often is NIDDM complicated with non-diabetic renal disease? An analysis of renal biopsies and the literature. Diabetologia 1996;39:1638-45. 